Article

\title{
Elbow Extensors and Volar Flexors Strength Capacity and Its Relation to Shooting Performance in Basketball Players-A Pilot Study
}

\author{
Darjan Smajla ${ }^{1,2}$, Žiga Kozinc ${ }^{1,3}$ and Nejc Šarabon ${ }^{1,2,3,4, * \mathbb{D}}$ \\ 1 Faculty of Health Sciences, University of Primorska, 6310 Izola, Slovenia; darjan.smajla@fvz.upr.si (D.S.); \\ ziga.kozinc@fvz.upr.si (Ž.K.) \\ 2 Innorenew CoE, Livade 6, 6310 Izola, Slovenia \\ 3 Andrej Marušič Institute, University of Primorska, 6000 Koper, Slovenia \\ 4 Laboratory for Motor Control and Motor Behaviour, S2P, Science to Practice, Ltd., 1000 Ljubljana, Slovenia \\ * Correspondence: nejc.sarabon@fvz.upr.si; Tel.: +38-6040-429-505
}

Received: 23 September 2020; Accepted: 17 November 2020; Published: 19 November 2020

\begin{abstract}
Rate of force/torque development scaling factor (RFD-SF/RTD-SF) has been used as a tool for assessing neuromuscular quickness. The aim was to investigate strength capacities of two major shooting muscle groups and their relationship to basketball shooting performance, and to compare the RFD-SF as well as shooting performance between junior and senior basketball players, and finally to examine the differences in RTD-SF between elbow extensors and volar flexors. In 23 male basketball players (13 juniors and 10 seniors) we assessed maximal isometric torque ( $\left.\mathrm{T}_{\mathrm{MVC}}\right)$, maximal rate of torque development and RTD-SF slope $\left(\mathrm{k}_{\mathrm{RTD}} \mathrm{SF}\right)$ for elbow extensors and volar flexors. The subjects performed 10 throws at $2.3 \mathrm{~m}$ (short) and $8.9 \mathrm{~m}$ (long) from the basket. Our results showed similar $\mathrm{k}_{\mathrm{RTD}-\mathrm{SF}}$ and $\mathrm{T}_{\mathrm{MVC}}$ in both groups. Better shooting performance from short distance was observed in senior players. Significant associations between $\mathrm{k}_{\mathrm{RTD}-\mathrm{SF}}, \mathrm{T}_{\mathrm{MVC}}$ and shooting performance were found only in juniors. Elbow extensors $\mathrm{T}_{\mathrm{MVC}}$ was found to have a significant positive large association with shooting performance from long distance. It seems that muscle capacity has an important role in shooting performance in junior compared to players. Sufficient strength capacity of major shooting muscles is important for juniors' shooting performance from a long distance.
\end{abstract}

Keywords: wrist; elbow; shot; accuracy; RFD-SF

\section{Introduction}

Rate of force development scaling factor (RFD-SF) has been used to quantify the ability to generate force rapidly, which is described as neuromuscular quickness [1]. A large number of studies have reported the RFD-SF as a reliable method for a number of muscle groups such as index finger abductors [1,2], elbow extensors [1,3], knee extensors [1,4] and various hip muscles [5]. However, the relationship between RFD-SF and performance in functional or sports-related tasks has not been yet investigated. It is known that muscle quickness decreases with age [2] or disease [6], while the influence of the specific training history on this ability is still, to a great extent, unknown.

Explosive and quick release during basketball shot is important to avoid the defender reaction. One of the studies showed positive effects of explosive strength training on the shot percentage level. However, explosive strength training was performed for upper and lower limb; therefore, it is unknown if upper limb strength capacities play important role in basketball shooting performance [7]. We speculate that upper limb strength capacities may be important for accurate shooting performance because it has been reported that an increase in maximum strength of elbow extensors positively affected the shoot accurately in the three-point shot [8]. 
Basketball shot is among the sports-specific movements in which rapid production of submaximal force by muscles that act across multiple arm joints is considered important. During a basketball throw, the players manipulate their shoulder, elbow, and wrist to generate the optimal ball speed and angular velocity of the joint at the time of the release [9], depending on the distance and the position from the basket. The angular velocity of the upper arm joints and the speed of ball release increase with the shooting distance [10], which suggests that higher submaximal involvement of the major muscle groups is required as the distance increases. The elbow extensors have been suggested as major contributors to release speed in basketball shooting [11,12] as they extend the elbow joint before release, while the activation of the volar flexors is an important component of shooting that optimises impulse applied to the ball at release [13]. Previous studies have reported that the angular velocity of the elbow joint of the shooting arm at release increases with distance from the basket, while the opposite is observed for the wrist [11], suggesting that the roles of the two joints vary with the shooting distance. Some earlier studies reported that players with more training experience had better shooting performance $[12,14]$ and lower average duration of arm muscle activation $[15,16]$. Based on this, we assumed that junior and senior players might also differ in the neuromuscular quickness of the major shooting muscles (i.e., elbow extensors and volar flexors). Furthermore, the relationship between neuromuscular quickness and performance of sport-specific tasks has not yet been investigated. Filling these missing gaps could contribute to better understanding of RFD-SF and its use during routine testing of the athletes and possibly, based on these assessments, to individualized guidance of training programmes (e.g., more emphasis on speed-power training for individuals with lower RTD or RTD-SF).

To contribute our part in clarification of the functional role of the RTD-SF in sport-specific performance, we conducted a study to investigate strength capacities of elbow extensors and volar flexors in two groups of basketball players (juniors and seniors) and their relationship to shooting performance, put into the sport-specific training history. Specifically, the first aim of our study was to investigate the differences in the strength capacities (RTD-SF slope ( $\left.\mathrm{k}_{\mathrm{RTD}-\mathrm{SF}}\right)$, maximum torque $\left(\mathrm{T}_{\mathrm{MVC}}\right)$, and peak rate of torque development (RTD PEAK) of elbow extensors (EE) and volar flexors (VF) and the shooting performance between junior and senior basketball players. We hypothesised that senior players, based on their longer training history and complete physical development, have significantly higher strength capacities of elbow extensors and volar flexors and better shooting performance compared to junior players. The second aim of the study was to investigate the relationship between the strength capacities ( $\mathrm{k}_{\mathrm{RTD}-\mathrm{SF}} \mathrm{T}_{\mathrm{MVC}}$, and RTD $\mathrm{PEAK}$ ) and shooting performance. We hypothesised that in both groups, shooting performance would be significantly positively associated with $\mathrm{k}_{\mathrm{RTD}}$-SF, $\mathrm{T}_{\mathrm{MVC}}$, and RTD PEAK of elbow extensors and volar flexors, at least from the long shooting distance. The third aim of the study was to investigate associations of elbow extensors and volar flexors as previous studies showed positive associations of $\mathrm{k}_{\mathrm{RTD}-\mathrm{SF}}$ ability for different muscle groups, while this association between elbow extensors and volar flexors has not yet been confirmed. We hypothesised that there will be a large and statistically significant association in $\mathrm{k}_{\mathrm{RTD}} \mathrm{SF}$ between elbow extensors and volar flexors in both groups of players, which might support the idea of a central regulation and upper extremity (not a single joint, i.e., muscle group) related characteristics of RTD-SF ability.

\section{Materials and Methods}

\subsection{Subjects}

A total of 23 male basketball players from the top-ranked Slovenian basketball club were included in the study (Table 1). All subjects reported their right arm as the preferred shooting arm. Subjects with previous upper limb injuries (past 6 months), neurological disorders, low back pain, or recent general illness were excluded from the study. The inclusion criteria were regular basketball training in past 3 years at least 4 times per week. The subjects and their parents/guardians were informed about the testing procedures and provided written informed consent prior to commencing the study. 
The experiment was approved by the Slovenian Medical Ethics Committee (approval no. 0120-99/2018/5) according to the Declaration of Helsinki.

Table 1. Characteristics of Subjects.

\begin{tabular}{ccccccc}
\hline Group & N & Age (years) & $\begin{array}{c}\text { Body } \\
\text { Height }(\mathbf{c m})\end{array}$ & $\begin{array}{c}\text { Body Mass } \\
\mathbf{( k g )}\end{array}$ & BMI & $\begin{array}{c}\text { Training History } \\
\text { (Years) }\end{array}$ \\
\hline Junior & 13 & $16.5 \pm 0.9$ & $192.7 \pm 7.8$ & $81.5 \pm 9.1$ & $21.9 \pm 2.0$ & $5.5 \pm 1.8$ \\
Senior & 10 & $24.0 \pm 4.2$ & $198 \pm 7.9$ & $95.5 \pm 10.9$ & $24.2 \pm 1.6$ & $14.1 \pm 3.8$ \\
Total & 23 & $19.7 \pm 4.8$ & $195.2 \pm 8.2$ & $87.6 \pm 11.9$ & $22.9 \pm 2.1$ & $9.3 \pm 5.2$ \\
\hline
\end{tabular}

N-the number of participants; BMI—Body mass index.

\subsection{Study Design and Testing Procedures}

For each subject, we captured measurements of (i) $\mathrm{k}_{\mathrm{RTD}-\mathrm{SF}}, \mathrm{T}_{\mathrm{MVC}}$, and RTD PEAK for EE and VF of the self-reported preferred arm and (ii) shooting performance at two different distances from the basket in two separate visits. On the first measurement day, the subjects performed isometric strength tests for $\mathrm{EE}$ and VF (random order) preceded by a $10 \mathrm{~min}$ warm-up consisting of $5 \mathrm{~min}$ of light running, 4 min of dynamic stretching, and $1 \mathrm{~min}$ of activation exercises (10 repetitions of squats, push-ups, and V-ups). The isometric strength tests were performed before their regular training in the laboratory setting. The next day, on the second measurement day, the subjects performed 10 throws at two different distances (random order) from the basket after the standardized warm-up protocol described before. The shooting performance was assessed in the gym basketball gym before their regular training. The flowchart of the study is outlined on the Figure 1.

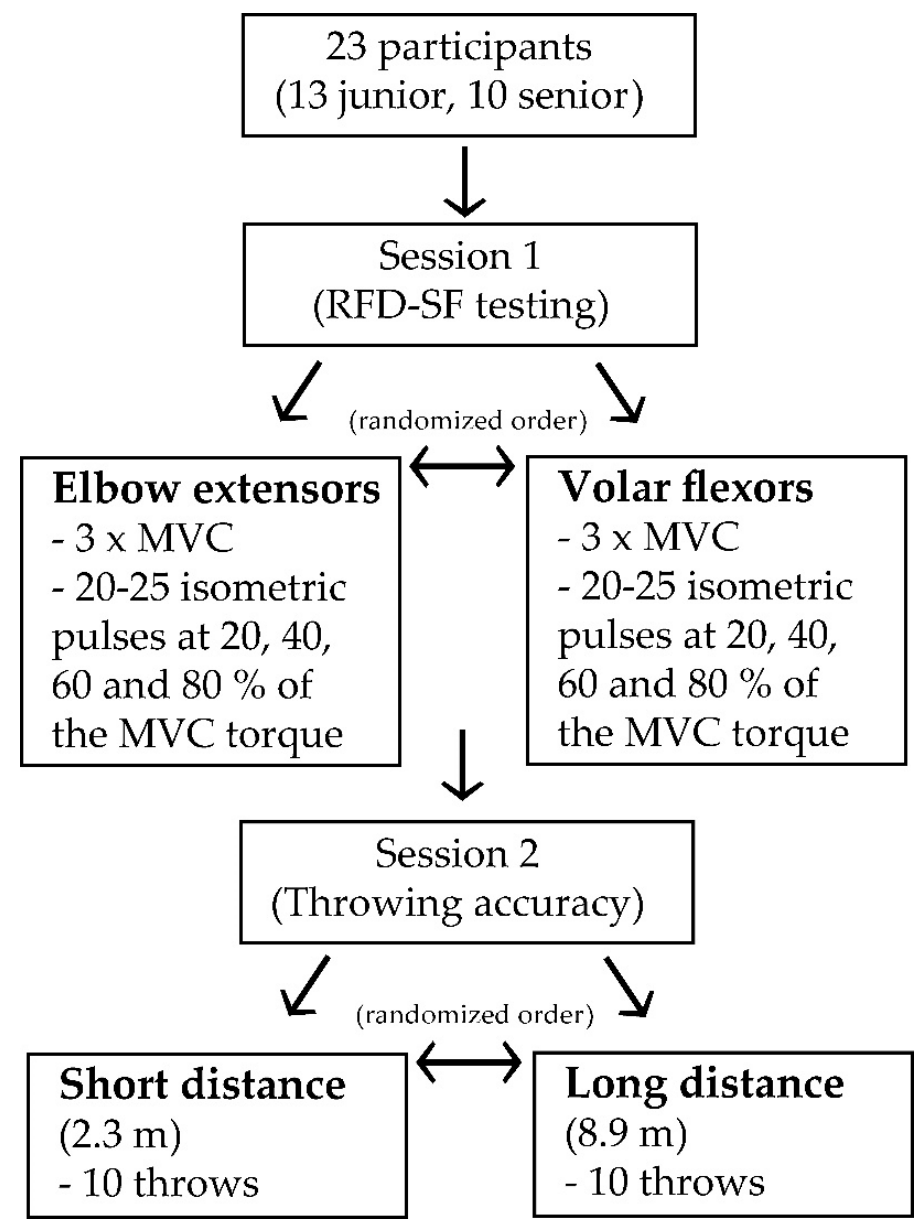

Figure 1. The flowchart of the measurement protocols. MVC-maximal voluntary isometric contraction. 
Following the warm-up, the subject was positioned in a custom-made dynamometer (S2P, Science to Practice, ltd., Ljubljana, Slovenia) which was used for $\mathrm{T}_{\mathrm{MVC}}$ and RTD PEAK and $\mathrm{k}_{\mathrm{RTD}}$-SF assessment. Participants position during elbow extension or volar flexion $\mathrm{T}_{\mathrm{MVC}}$, $\mathrm{RTD}_{\mathrm{PEAK}}$, and $\mathrm{k}_{\mathrm{RTD}-\mathrm{SF}}$ assessment is presented and described in Figure 2. In all cases, the lever arm (i.e., the linear distance from the axis of the joint and the centre of the distal force-detecting support) was measured and considered in the torque calculation. The signals from force transducers during elbow extension (Bending beam load cell 1-Z6FC3/200kg, HBM, Darmstadt, Germany) and volar flexion (Tension compression load cell FL25-50 kg, Forsentek, Shenzhen, China) were amplified (Isotel, Logatec, Slovenia) and converted from analogue to digital signal (NI USB-6211, National Instruments, Austin, TX, USA). Signals were sampled at $1000 \mathrm{~Hz}$ by a custom-made LabView 2015 software (National Instruments Corp., Augustin,

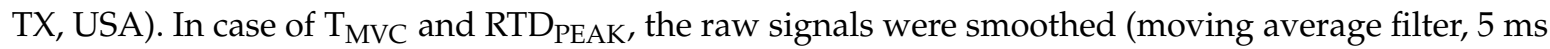
time-window). In RTD-SF analyses the signals were filtered using a lowpass Butterworth filter with cut-off frequency at $5 \mathrm{~Hz}$, while corresponding RTD of each contraction was calculated as a peak value of derivate of the torque curve [4]. All measurements were processed by a single investigator.
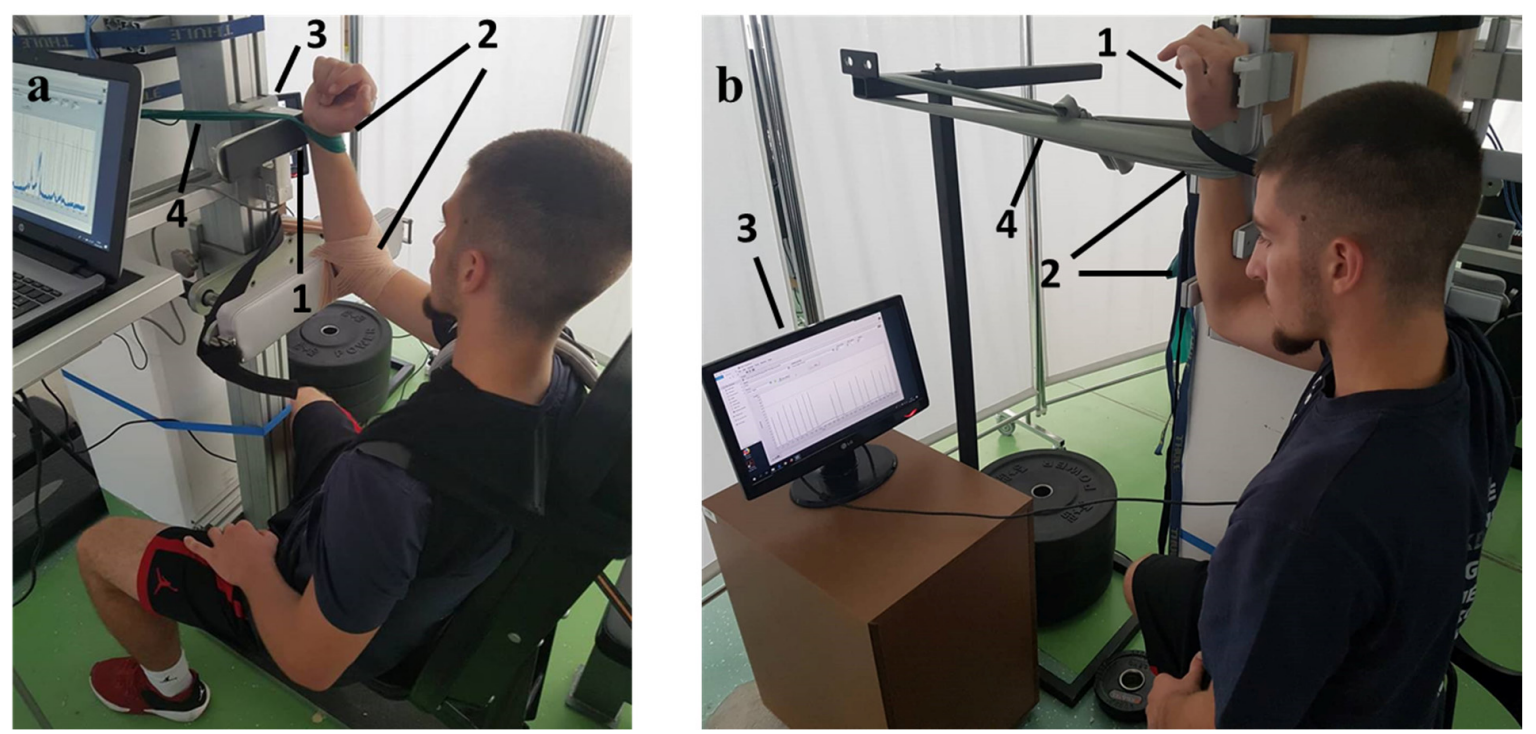

Figure 2. Measurement set-up: (a) Subject in the custom-built elbow extensor dynamometer. Subjects were seated (knee and hip in $90^{\circ}$ position, trunk in upright position) on a bench with back support, while their shoulder and elbow were flexed at $90^{\circ}$ in sagittal plane (forearm was in neutral position). The trunk and the shoulder of the performing arm were fixed to the back support, while the elbow was fixated to the lower support of the dynamometer. The force sensor was at the upper support, where the subject placed the wrist, which was fixated using elastic bands (to provide tension and proper contact between wrist and dynamometer support). (b) Subject in the custom-built volar flexor dynamometer. Subjects were seated on a chair. The subject's shoulder and elbow were both flexed at $90^{\circ}$, while their forearm (pronated position) was placed in a custom-made dynamometer which allows full forearm fixation. Wrist was in neutral position. 1-force sensor, 2-joint fixations, 3-monitor for visual feedback, 4-elastic band

\subsection{Testing $T_{M V C}$ and $R T D_{P E A K}$}

In $\mathrm{T}_{\mathrm{MVC}}$ testing subjects were instructed to gradually increase the force and push as hard as possible against the elbow (Figure 2a) and wrist dynamometer's support (Figure 2b). Contractions were sustained for at least $3 \mathrm{~s}$; meanwhile, verbal encouragement was given to the subject. $T_{M V C}$ for each muscle group was calculated $(\mathrm{Nm} / \mathrm{kg})$ as the maximal mean value on a $1 \mathrm{~s}$ time interval. Each participant performed three repetitions for each muscle group. The greatest $\mathrm{T}_{\mathrm{MVC}}$ was used for statistical analysis. 
Three isometric MVCs for each muscle group (EE and VF) with a $60 \mathrm{~s}$ rest between trials were repeated, while in this case subjects were instructed to push as hard and explosive as possible to calculate their RTD PEAK (maximum of the toque-time derivative). Greatest $\operatorname{RTD}_{\text {PEAK }}(\mathrm{Nm} / \mathrm{kg} \mathrm{s}$ ) was used for statistical analysis.

\subsection{Testing RTD-SF}

The RTD-SF relationship for each muscle group was computed from sets of 20-25 explosive isometric contractions at four different submaximal intensities $\left(20 \%, 40 \%, 60 \%\right.$, and $80 \%$ of $\left.\mathrm{T}_{\mathrm{MVC}}\right)$ (Figure 3a,c) in a random order, as previously described [1]. Subjects rested for $60 \mathrm{~s}$ between different contraction intensities and $3 \mathrm{~min}$ between each task, i.e., muscle group. The target torque was displayed as a horizontal line on a graph on a computer screen placed at the subject's eye level (Figure 2). The subjects were instructed to contract and relax as fast as possible.
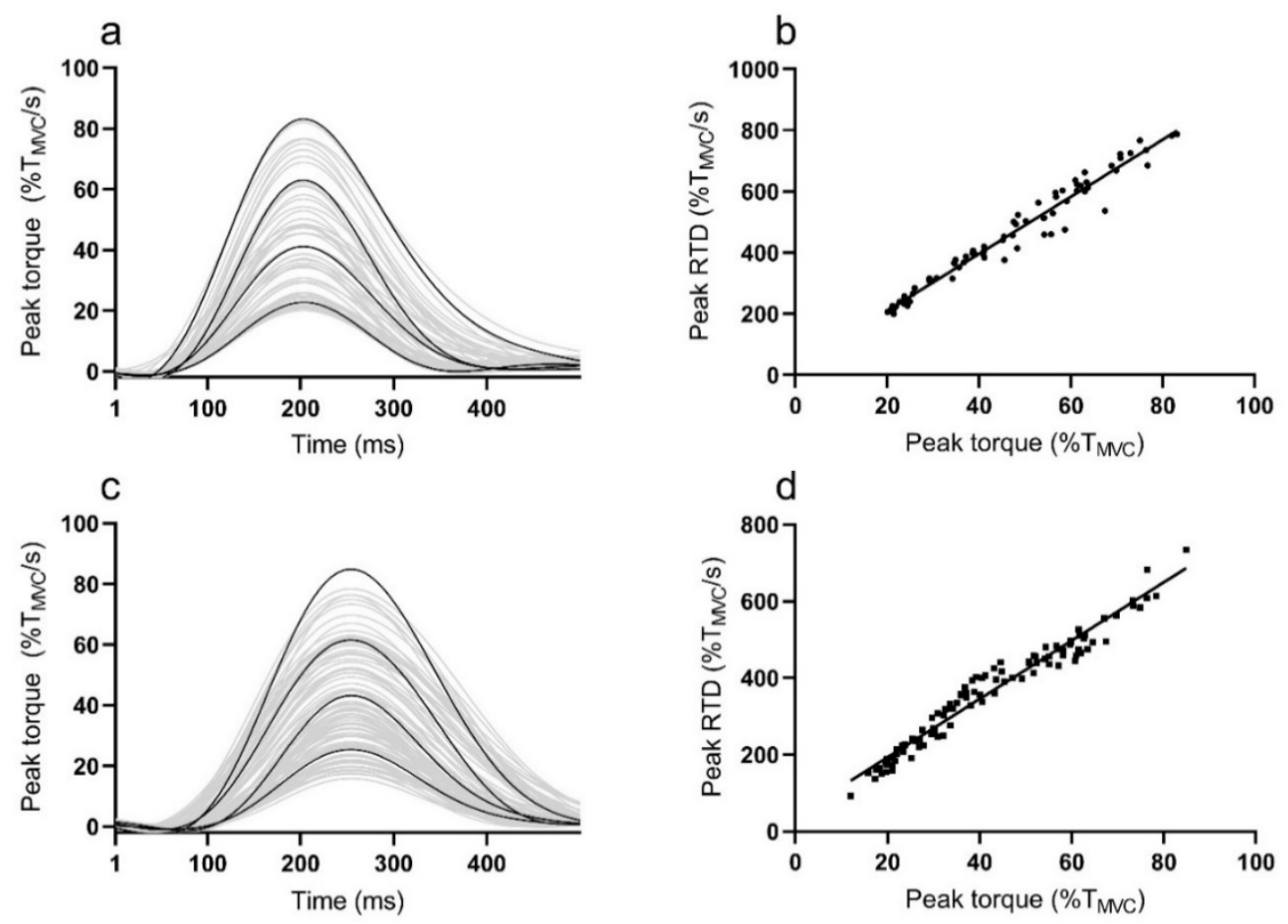

Figure 3. Sample recording of rapid torque pulses of (a) elbow extensors and (c) volar flexors to a variety of amplitudes. Rate of torque development scaling factor (RTD-SF) plot of (b) elbow extensors (b) and (d) volar flexors with data points taken from the peaks of the preferred arm.

The regression parameters $\mathrm{k}_{\mathrm{RTD}-\mathrm{SF}}(/ \mathrm{s})$ and $\mathrm{r}^{2}$ RTD-SF were obtained from the relationship between the peak torque and the corresponding peak RTD.

\subsection{Testing Shooting Performance}

During the second visit, the subjects performed 10 throws at two different distances, orientated frontally towards the basket. Shooting distances were selected in random order for each subject. Shooting performance from short distance was performed from half the distance between the basket and free throw line $(2.3 \mathrm{~m})$, while shooting form the longer distance was performed from $8.9 \mathrm{~m}$ (three-point line + distance between free throw and three-point line). From each subject shooting performance from each distance was assessed $(\mathrm{n} / 10)$. 


\subsection{Statistical Analysis}

Descriptive data of the dependent variables are presented as means and standard deviations. The Shapiro-Wilk test was used to assess data normality. Fisher's z-transformation was used to transform $r^{2}$ RTD-SF in case of RTD-SF to obtain normal distribution. The differences in $k_{R T D-S F}, T_{M V C}$, and RTD ${ }_{\text {PEAK }}$ between groups were evaluated with a two-tailed independent sample t-test and Cohen's $\mathrm{d}$ effect size (ES). The ES was interpreted as negligible $(<0.2)$, small $(0.2-0.5)$, moderate $(0.5-0.8)$, and large $(\geq 0.8)$ [17]. Pearson correlation coefficients were used to determine the relationship between $\mathrm{k}_{\mathrm{RTD}-\mathrm{SF}}, \mathrm{T}_{\mathrm{MVC}}$, and RTD $\mathrm{PEAK}_{\mathrm{K}}$ of $\mathrm{EE}$ and VF and shooting performance from short and long distance. The correlation coefficient was interpreted in as (0.00-0.19 trivial; $0.10-0.29$ small; $0.30-0.49$ moderate; 0.50-0.69 large; 0.70-0.89 very large; 0.90-0.99 nearly perfect; and 1.00 perfect) [18]. Moreover, we assessed the reliability of $\mathrm{k}_{\mathrm{RTD}-\mathrm{SF}}, \mathrm{T}_{\mathrm{MVC}}$, and RTD $\mathrm{PEAK}$ by calculating two-way random model intra-class correlation coefficients (ICC) for single measures and standard error of measurement,

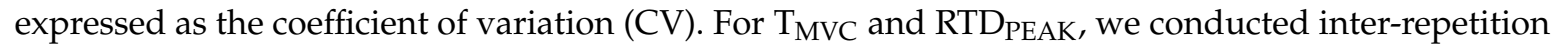
reliability, while for the RFD-SF, we split the data from each intensity into two halves, and compared $\mathrm{k}_{\text {RTD-SF }} \mathrm{r}^{2}$ RTD-SF obtained from both subsets of the data. The level of statistical significance was set at $p<0.05$. Statistical analyses were performed using the SPSS (IBM SPSS version 26.0, Chicago, IL, USA) software package.

\section{Results}

The reliability of the outcome variables is shown in Table 2. For both muscle groups RTD-SF and $\mathrm{T}_{\mathrm{MVC}}$ showed very good reliability (all ICC $\geq 0.85$; all $\mathrm{CV} \leq 5.66 \%$ ); however, the reliability was somewhat lower for RTD PEAK, especially for the VF muscles (ICC $=0.54 ; \mathrm{CV}=15.21 \%$ ).

Table 2. Reliability of the outcome variables.

\begin{tabular}{cccc}
\hline \multicolumn{2}{c}{ Muscle Group/Variable } & ICC & CV \\
\hline \multirow{4}{*}{ Elbow extensors } & $\mathrm{T}_{\text {MVC }}$ & $0.91(0.85-0.96)$ & $2.34(1.02-3.49)$ \\
& RTD & $0.78(0.55-0.92)$ & $7.89(3.44-12.75)$ \\
& k $_{\text {RFD-SF }}$ & $0.99(0.97-1.00)$ & $1.23(0.97-2.03)$ \\
& $\mathrm{r}^{2}$ RFD-SF & $0.88(0.76-0.96)$ & $1.05(0.54-1.61)$ \\
\hline \multirow{5}{*}{ Volar flexors } & $\mathrm{T}_{\text {MVC }}$ & $0.85(0.72-0.94)$ & $5.66(2.81-8.44)$ \\
& RTD & $0.54(0.23-0.84)$ & $15.211(8.76-21.12)$ \\
& $\mathrm{k}_{\text {RFD-SF }}$ & $0.99(0.96-1.00)$ & $1.71(1.11-2.58)$ \\
& $\mathrm{r}^{2}$ RFD-SF & $0.87(0.67-0.96)$ & $5.45(2.36-9.21)$ \\
\hline
\end{tabular}

$\mathrm{k}_{\mathrm{RTD}-\mathrm{SF}}-$ slope of regression line, $\mathrm{r}^{2} \mathrm{RTD}-\mathrm{SF}$ - linearity of regression line, $\mathrm{T}_{\mathrm{MVC}}-$ maximal torque normalized on body weight, RTD PEAK - maximal rate of torque development normalized on body weight.

Junior players had a significantly lower average number of training years ( $5.5 \pm 1.8$ years) compared to senior players $(14.1 \pm 3.8$ years $)\left(\mathrm{t}_{(21)}=-7.2, p<0.013\right)$. There was no statistically significant difference in height between groups $\left(\mathrm{t}_{(21)}=-1.6, p=0.11\right)$, while senior players had statistically significantly higher body mass $\left(\mathrm{t}_{(21)}=-3.4, p=0.003\right)$ and body mass index $(\mathrm{BMI})\left(\mathrm{t}_{(21)}=-3.0, p=0.007\right)$. Average $\mathrm{k}_{\mathrm{RTD}-\mathrm{SF}}, \mathrm{T}_{\mathrm{MVC}}$, and RTD $\mathrm{PEAK}_{\mathrm{K}}$ values of elbow extensors and volar flexors in junior and senior group are presented in Table 3. Junior and senior players had similar values of $\mathrm{T}_{\mathrm{MVC}}$ in both muscle groups, while junior players had significantly greater RTD $\mathrm{PEAK}_{\mathrm{K}}$ of EE and VF ( $p=0.003-0.005$, ES $\left.=0.35-0.36\right)$. For both groups, a strong linear relationship $\left(r^{2}\right.$ RTD-SF $\left.=0.93-0.95\right)$ between the peak force and the RFD across submaximal contractions was calculated for both muscle groups (sample recordings are presented in Figure 3). There was no statistically significant difference in $\mathrm{k}_{\mathrm{RTD} \text {-SF }}$ between junior and senior players for elbow extensors or volar flexors. There was no difference in shooting performance from long distance, whereas senior players were more successful from short distance. 
Table 3. Descriptive statistics and differences in measured parameters between junior and senior basketball players.

\begin{tabular}{ccccccc}
\hline \multicolumn{2}{c}{ Muscle Group/Variable } & Junior & Senior & $t$ & $p$ & ES \\
\hline \multirow{4}{*}{ Elbow } & $\mathrm{k}_{\text {RTD-SF }}(/ \mathrm{s})$ & $8.9 \pm 0.9$ & $8.5 \pm 1.2$ & 0.46 & 0.65 & 0.009 \\
extensors & $\mathrm{r}^{2}$ RTD-SF & $0.95 \pm 0.04$ & $0.93 \pm 0.07$ & 0.98 & 0.34 & 0.04 \\
& $\mathrm{~T}_{\text {MVC }}(\mathrm{Nm} / \mathrm{kg})$ & $0.70 \pm 0.13$ & $0.74 \pm 0.16$ & -0.65 & 0.6 & 0.01 \\
& $\mathrm{RTD}_{\text {PEAK }}(\mathrm{Nm} / \mathrm{kg} \mathrm{s})$ & $9.9 \pm 0.9$ & $8.3 \pm 1.3$ & 3.45 & 0.005 & 0.36 \\
\hline \multirow{4}{*}{ Volar flexors } & $\mathrm{k}_{\text {RTD-SF }}(/ \mathrm{s})$ & $7.5 \pm 1.0$ & $7.3 \pm 1.8$ & 0.87 & 0.39 & 0.04 \\
& $\mathrm{r}^{2}$ RTD-SF & $0.93 \pm 0.04$ & $0.94 \pm 0.05$ & -0.35 & 0.73 & 0.006 \\
& $\mathrm{~T}_{\text {MVC }}(\mathrm{Nm})$ & $0.21 \pm 0.07$ & $0.23 \pm 0.03$ & -0.5 & 0.63 & 0.02 \\
& $\mathrm{RTD}_{\text {PEAK }}(\mathrm{Nm} / \mathrm{kg} \mathrm{s})$ & $9.2 \pm 1.5$ & $7.2 \pm 1.3$ & 3.3 & 0.003 & 0.35 \\
\hline Shooting & Short distance $(\%)$ & $8.6 \pm 1.2$ & $10.0 \pm 0.0$ & -3.9 & 0.02 & 0.56 \\
performance & Long distance $(\%)$ & $4.8 \pm 2.2$ & $6.3 \pm 2.1$ & -1.7 & 0.1 & 0.12
\end{tabular}

$\mathrm{k}_{\text {RTD-SF}}$-slope of regression line, $\mathrm{r}^{2}$ RTD-SF -linearity of regression line, $\mathrm{T}_{\mathrm{MVC}}$-maximal torque normalized on body weight, $\mathrm{RTD}_{\mathrm{PEAK}}$ - maximal rate of torque development normalized on body weight, Short distance—shooting distance at $2.3 \mathrm{~m}$ from the basket, Long distance-shooting distance at $8.9 \mathrm{~m}$ from the basket.

Significant associations between $\mathrm{k}_{\mathrm{RTD}-\mathrm{SF}}, \mathrm{T}_{\mathrm{MVC}}$, RTD $\mathrm{PEAK}$ (EE and VF) with shooting performance for junior players are presented in Figure 4. We calculated a large positive association between $\mathrm{k}_{\mathrm{RTD}-\mathrm{SF}}$ of EE and VF and shooting performance from short distance (Figure 4a,b), while significant negative large associations were seen between $\mathrm{k}_{\mathrm{RTD}} \mathrm{SF}$ of both muscle groups and shooting performance from long distance (Figure 4c,d). Moreover, a significant positive large association was calculated between $\mathrm{T}_{\mathrm{MVC}}$ of $\mathrm{EE}$ and shooting performance from long distance (Figure 4e), while the association between $\mathrm{T}_{\mathrm{MVC}}$ of VF and shooting performance was not statistically significant (Figure 4f). No statistically significant associations were calculated in junior players between RTD $_{\text {PEAK }}$ of both muscle groups and shooting performance $(r=0.246-0.315, p=0.48-0.49)$. There were no significant associations between $\mathrm{T}_{\mathrm{MVC}}, \mathrm{RTD}_{\mathrm{PEAK}}$, or $\mathrm{k}_{\mathrm{RTD}-\mathrm{SF}}(\mathrm{EE}$ and $\mathrm{VF})$ and any shooting performance in senior basketball players $(\mathrm{r}=-0.481-0.481, p=0.15-0.55)$ or in both groups combined $(\mathrm{r}=-0.366-0.271, p=0.16-0.87)$.

Significant positive large associations between $\mathrm{k}_{\mathrm{RTD}} \mathrm{SF}$ of elbow extensors and volar flexors were calculated for senior group $(r=0.677, p<0.05)$ and when both groups were evaluated together $(\mathrm{r}=0.615, p<0.001)$, while associations between $\mathrm{k}_{\mathrm{RTD}-\mathrm{SF}}$ of elbow extensors and volar flexors in junior group were not statistically significant $(\mathrm{r}=0.514, p=0.72)$.
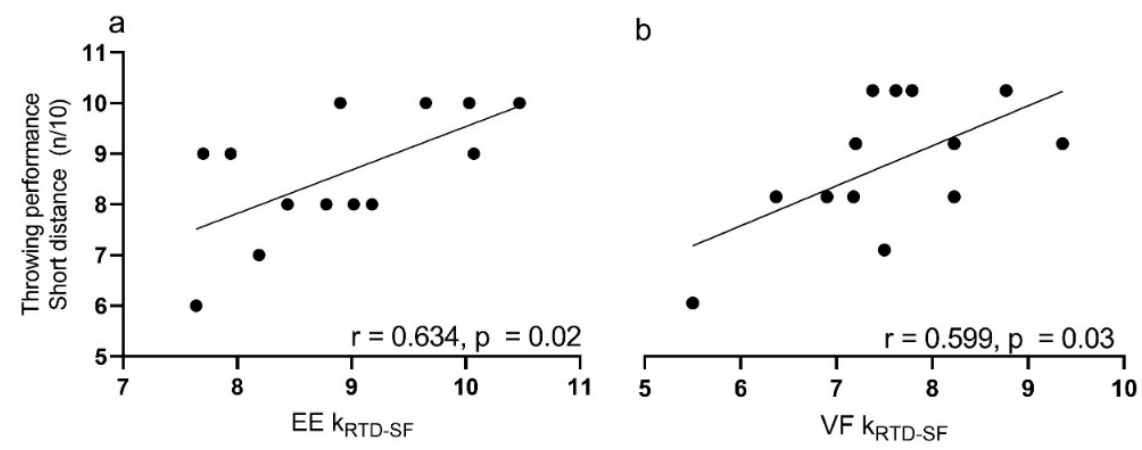

Figure 4. Cont. 

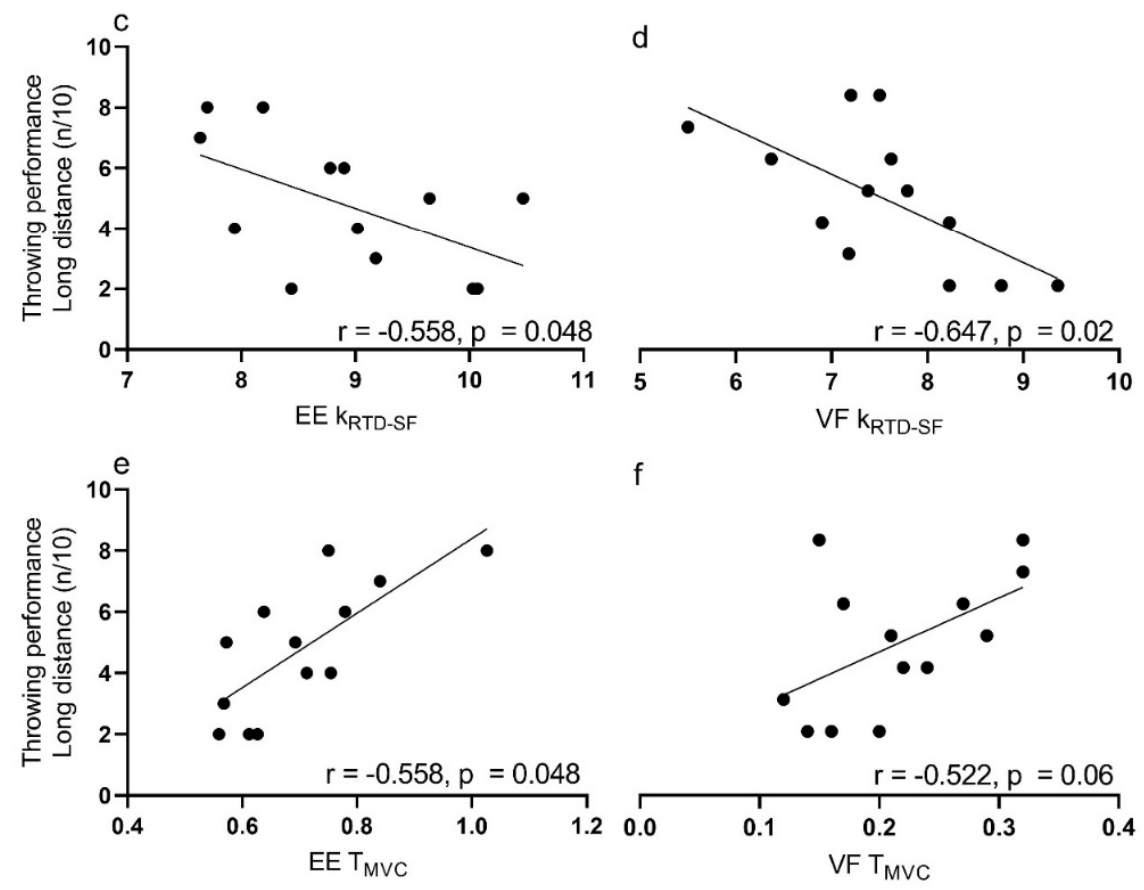

f

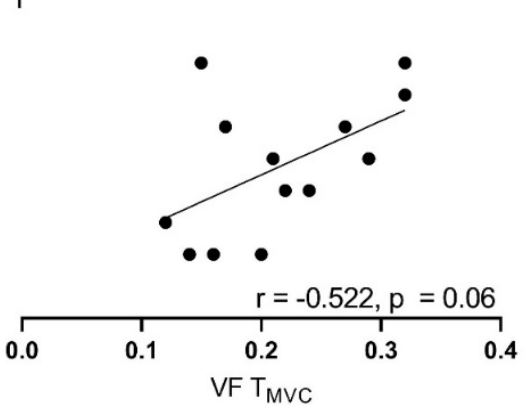

Figure 4. Associations between $\mathrm{k}_{\mathrm{RTD}-\mathrm{SF}}(\mathbf{a}-\mathbf{d}), \mathrm{T}_{\mathrm{MVC}}(\mathbf{e}, \mathbf{f})$ of elbow extensors (EE) or volar flexors (VF) and shooting performance from short and long distance.

\section{Discussion}

The first aim of our study was to investigate differences in strength capacities of elbow extensors and volar flexors and shooting performance between junior and senior basketball players. Our results showed similar $\mathrm{k}_{\mathrm{RTD}-\mathrm{SF}}$ of both muscle groups between juniors and seniors regardless of significant differences between the two groups regarding training history, body mass and BMI. Similar values were also observed for $\mathrm{T}_{\mathrm{MVC}}$ of both groups, while juniors had significantly greater RTDPEAK (normalized to body weight). Seniors showed better shooting performance only at short distance compared to junior players. The second aim was to investigate associations between strength capacities and shooting performance. Significant associations between $\mathrm{k}_{\mathrm{RTD}-\mathrm{SF}}$ of both muscle groups and shooting performance were found only in juniors. Our results revealed significant positive association between $\mathrm{k}_{\mathrm{RTD}} \mathrm{SF}$ of elbow extensors, volar flexors and shooting performance from short distance. On the contrary, a significant negative large association was found between $\mathrm{k}_{\mathrm{RTD}} \mathrm{SF}$ of both muscle groups and shooting performance from long distance. $\mathrm{T}_{\mathrm{MVC}}$ of elbow extensors was found to have a significant positive large association with shooting performance from long distance. Our third aim was to investigate associations in $\mathrm{k}_{\mathrm{RTD}-\mathrm{SF}}$ of elbow extensors and volar flexors. Our results showed significant positive large associations between $\mathrm{k}_{\mathrm{RTD}} \mathrm{SF}$ of elbow extensors and volar flexors.

In this study, we investigated the $\mathrm{k}_{\mathrm{RTD}-\mathrm{SF}}, \mathrm{T}_{\mathrm{MVC}}$, and RTD PEAK of two major groups of arm muscles that generate force that is necessary for the execution of the basketball shot. RTD-SF has already been shown to be sensitive to changes in neuromuscular function associated with age [2] and disease [6]. As it was shown that explosive strength training positively influences shooting accuracy in basketball players [7], and moreover, there are some indices that maximum strength of elbow extensors is positively associated with shooting accuracy in the three-point shot, our goal was to further investigate the relationship between upper limb strength capacity and shooting performance. We hypothesized that a sport-specific movement that is constantly repeated (such as basketball shooting) might have an influence on strength capacities ( $\mathrm{k}_{\mathrm{RTD}-\mathrm{SF}}, \mathrm{T}_{\mathrm{MVC}}$, and $\mathrm{RTD} \mathrm{DEAK}_{\mathrm{P}}$ ) of the responsible muscle groups, and in addition, it might be dependent on the training history and physical development. On this basis, we evaluated differences between junior and senior basketball players in terms of $k_{\text {RTD-SF }}, T_{M V C}$, 
and RTD ${ }_{\text {PEAK }}$ of EE and VF. The senior basketball players had significantly longer participation in basketball training and consequently greater experience and completed maturation.

Previous studies have shown that players with more training experience had better free-throw performance compared to less-experienced players [12,14]. Moreover, it was shown that explosive strength training of upper and lower limb improves basketball shooting accuracy [7]. In our study, we investigated shooting performance from shorter and longer, as different shooting distances may require different involvement of muscle strength capacities. Although it is known that muscle growth is occurring in boys until 17.5 years of age [19], our results showed that juniors and seniors had similar strength capacities of elbow extensors and volar flexors, with the exception of RTD PEAK. Significantly

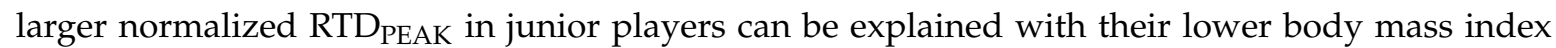
(Table 1), since it is known that lean body mass is associated with greater RFD/RTD [20]. On the other hand, differences in abilities such as $\mathrm{k}_{\mathrm{RTD}} \mathrm{SF}$, which is independent of the body mass and muscle size, have not yet been investigated in relation to age. $\mathrm{T}_{\mathrm{MVC}}$ of elbow extensors, volar flexors as well as $\mathrm{k}_{\mathrm{RTD}-S F}$ values of both muscle groups showed similar values in junior and senior basketball players (Table 3). There is a paucity of literature analysing the differences in muscle capacity between junior and senior elite basketball players, especially regarding the upper body. A previous study reported that senior basketball players produce significantly higher absolute power with lower extremities [21]. Our data suggest that there is no difference in neuromuscular quickness (as tested by $\mathrm{k}_{\mathrm{RTD}-\mathrm{SF}}$ ), between juniors and seniors. On the other hand, some studies that assessed shooting and passing actions showed that more experienced basketball players exhibit a shorter duration of muscle activation of the arm muscles $[15,16]$. This could be due to the changes in motor pattern activity associated with increasing skill [22] and not due to the changes in neuromuscular quickness. In accordance with previous studies $[12,14]$, we have also confirmed that the players with more training experience have better shooting performance, but only from short distance. It is known that the shooting movement pattern changes with greater shooting distance, while its accuracy significantly decreases [23]. Overall, our results suggest that senior players do not have higher strength capacities compared to junior players, while they are equalized in shooting performance at long shooting distance. Thus, we can reject our first hypothesis.

Shooting performance was related with $\mathrm{k}_{\mathrm{RTD}-\mathrm{SF}}$ and $\mathrm{T}_{\mathrm{MVC}}$ only in junior players. This result suggests that muscle abilities such as neuromuscular quickness and $\mathrm{T}_{\mathrm{MVC}}$ play an important role in shooting performance only in junior players, whereas in seniors their shooting muscles exceed the level of strength capacities required for successful shooting performance. In more experienced players, the shooting performance is influenced by the pattern of muscle activity (i.e., shorter or longer duration from the beginning of muscle activity, lower average activation time) $[15,16]$ and likely not by the capacity of the shooting muscles. A very strong positive association between elbow extensor $\mathrm{T}_{\mathrm{MVC}}$ and shooting performance from long distance shows that muscle strength is more important for shooting performance from longer distance in juniors compared to seniors. On the contrary there was no associations between $\mathrm{T}_{\mathrm{MVC}}$ and shooting performance from short distance. Junior players with higher elbow extensors $\mathrm{T}_{\mathrm{MVC}}$ were more successful at shooting performance from a long distance (Figure 4e), which highlights the importance of muscle strength in the accuracy task from such distance. We can speculate that junior players with a smaller $\mathrm{T}_{\mathrm{MVC}}$ were closer to their maximum strength capacity when they performed shots from a greater distance. This can be supported with findings from one study, which showed that the accuracy decreases when the shot is performed closer to the maximal strength capacity [24]. Such associations have been only approaching statistical significance for volar flexors. Likely, it seems that the elbow extensors play a more important role than wrist muscles in providing the force required for the ball to reach the basket at greater distances [11]. On the other hand, RTD PEAK was not associated with shooting performance which could be explained by the fact that basketball shots are not performed under conditions that acquire maximal rate of force development.

Significant large positive associations were calculated between $\mathrm{k}_{\mathrm{RTD}-\mathrm{SF}}$ of both muscle groups and the shooting performance from short distance in juniors, while $\mathrm{k}_{\mathrm{RTD}-\mathrm{SF}}$ of both groups was in 
large negative association with long distance. It seems that the execution of the shot from short distance was better suited to junior players with greater $\mathrm{k}_{\mathrm{RTD}-\mathrm{SF}}$, while the opposite holds true for the long-distance shots. A negative association between $\mathrm{k}_{\mathrm{RTD}-\mathrm{SF}}$ and shooting performance from long distance indicates that players with greater $\mathrm{k}_{\mathrm{RTD}} \mathrm{SF}$ have worse shooting performance from long distance. It is already known that basketball shots are performed at higher velocities as the distance from the basket is increased [13], while lower velocities are related to greater movement accuracy [25]. It has been shown that weaker players who are unable to generate sufficient force must use a strategy of generating greater segmental velocities in order to execute a shot [26]. Shot execution at higher velocities (due to the greater distance) increases body segments movement variability and decreased movement consistency [27], while shooting performance at lower velocities provides additional time and thus allows players to perform movement corrections with visual and proprioceptive feedback [28]. This could be supported by the results of another study in which novice handball players reduced their shooting accuracy when the shooting speed was increased, while this had no effect on the shooting accuracy of expert players [29]. However, we did not measure the kinematic characteristics of shot execution, which would be valuable information for further explanations of measured associations.

In addition, similar investigation on a larger sample size would be needed for further conclusions together with the kinematic analysis of the shot from few shooting distances, while contribution from lower limb should be also considered. Finally, although the sensors used to acquire force data were high-quality load cell models, the reliability of the exact set-up, as used in this study, has not been checked before. The inter-repetition reliability of the outcome variables was, however, mostly very good. Notably, RFD PEAK had $\mathrm{k}_{\mathrm{RTD}-\mathrm{SF}}$, which supports that the latter could be an important addition or alternative to commonly performed assessments ( $\mathrm{T}_{\mathrm{MVC}}$ and $\left.\mathrm{RTD}_{\mathrm{PEAK}}\right)$.

\section{Limitations of the Study}

An important limitation of our study is the lack of data about the kinematics of the shot execution (especially movement velocity), which could further explain the relationship between shooting performance and strength capacity. There are potentially other additional variables that influenced the shooting performance and were not controlled (e.g., release angle, release height, physical characteristics of the players, additional basketball skills and movements that occur before shot, the power generated by the leg muscles, etc.). Moreover, only male gender was evaluated so our conclusion refers only to young male basketball players.

\section{Conclusions}

This was the first study to investigate differences in $\mathrm{k}_{\mathrm{RTD}-\mathrm{SF}}$ and other strength capacities between juniors and seniors with significantly different training histories. It appears that the specific training history (performing basketball shot) has no influence on neuromuscular quickness of elbow extensors and volar flexors. Our results suggest that strength capacities, specifically $\mathrm{T}_{\mathrm{MVC}}$ is a limiting factor for successful shooting performance only in juniors, while in seniors there was no associations with strength capacities and shooting accuracy. This should be taken into account in training programmes of young male basketball players. Appropriate strength capacities, specifically maximum strength of elbow extensors should be developed for successful shooting performance for longer distance in young male basketball players. Detailed kinematic assessment of shooting performance should be measured in the future to confirm our assumptions that players with higher $k_{\text {RTD-SF }}$ use higher movement velocities at longer shooting distance, resulting in poorer shooting performance.

Author Contributions: Conceptualization, N.Š.; methodology, D.S., N.Š., and Ž.K.; software, N.Š.; formal analysis, D.S., N.Š., and Ž.K.; investigation, D.S.; resources, N.Š.; data curation, D.S. and Ž.K.; writing-original draft preparation, D.S.; writing-review and editing, N.Š. and Ž.K.; visualization, N.Š.; supervision, N.Š.; project administration, N.Š.; funding acquisition, N.Š. All authors have read and agreed to the published version of the manuscript. 
Funding: This research was funded by Slovenian research agency, grant number L5-1845: Body asymmetries as a risk factor in musculoskeletal injury development: studying etiological mechanisms and designing corrective interventions for primary and tertiary preventive care, (2) bilateral project between Slovenia and Serbia ARRS-BI-RS/18-19-010 and by the research program fund P5-0147 Kinesiology of monostructural, polystructural, and conventional sports.

Acknowledgments: Authors thank a student at the University of Primorska, Jure Muršec, for his help at subject's recruitment and data acquisition.

Conflicts of Interest: The authors declare no conflict of interest.

\section{References}

1. Bellumori, M.; Jaric, S.; Knight, C.A. The rate of force development scaling factor (RFD-SF): Protocol, reliability, and muscle comparisons. Exp. Brain Res. 2011, 212, 359-369. [CrossRef] [PubMed]

2. Bellumori, M.; Jaric, S.; Knight, C.A. Age-related decline in the rate of force development scaling factor. Motor Control 2013, 17, 370-381. [CrossRef] [PubMed]

3. Mathern, R.M.; Anhorn, M.; Uygur, M. A novel method to assess rate of force relaxation: Reliability and comparisons with rate of force development across various muscles. Eur. J. Appl. Physiol. 2019, 119, 291-300. [CrossRef] [PubMed]

4. Djordjevic, D.; Uygur, M. Methodological considerations in the calculation of the rate of force development scaling factor. Physiol Meas 2017, 39, 015001. [CrossRef] [PubMed]

5. Casartelli, N.C.; Lepers, R.; Maffiuletti, N.A. Assessment of the rate of force development scaling factor for the hip muscles. Muscle Nerve 2014, 50, 932-938. [CrossRef]

6. Uygur, M.; de Freitas, P.B.; Barone, D.A. Rate of force development and relaxation scaling factors are highly sensitive to detect upper extremity motor impairments in multiple sclerosis. J. Neurol. Sci. 2020, 408, 116500. [CrossRef]

7. Savaş, S.; Yüksel, M.F.; Uzun, A. The effects of rapid strength and shooting training applied to professional basketball players on the shot percentage level. Univers. J. Educ. Res. 2018, 6, 1569-1574. [CrossRef]

8. Justin, I.; Strojnik, V.; Sarabon, N. The effect of increased maximum strength of elbow extensors on the ability to shoot accurately in darts and the three-point shot in basketball. Rev. Šport Rev. za Teor. Prakt. V prašanja Športa 2006, 2, 51-55.

9. Okubo, H.; Hubbard, M. Kinematics of arm joint motions in basketball shooting. Procedia Eng. 2015, 112, 443-448. [CrossRef]

10. Miller, S.; Federation, I.T. The relationship between basketball shooting kinematics, distance and playing position. J. Sports Sci. 1996, 14, 243-253. [CrossRef]

11. Miller, S.; Bartlett, R.M. The effects of increased shooting distance in the basketball jump shot. J. Sports Sci. 1993, 11, 285-293. [CrossRef] [PubMed]

12. Button, C.; Macleod, M.; Sanders, R.; Coleman, S. Examining movement variability in the basketball free-throw action at different skill levels. Res. Q. Exerc. Sport 2003, 74, 257-269. [CrossRef] [PubMed]

13. Okazaki, V.H.A.; Rodacki, A.L.F.; Satern, M.N. A review on the basketball jump shot. Sports Biomech. 2015, 14, 190-205. [CrossRef] [PubMed]

14. Zuzik, P. Free Throw Shooting Effectiveness in Basketball Matches of Men and Women. Sport Sci. Rev. 2012, 20, 149-160. [CrossRef]

15. Pakosz, P.; Konieczny, M. Time Analysis of Muscle Activation during Basketball Free Throws. Cent. Eur. J. Sport Sci. Med. 2016, 15, 73-79. [CrossRef]

16. Pakosz Paweł Emg Signal Analysis of Selected Muscles During Shots and Passes in Basketball. J. Heal. Promot. Recreat. Rzesz. 2011, 2, 8-14.

17. Cohen, J. Statistical Power Analysis for the Behavioral Sciences, 2nd ed.; Routlege Academic: New York, NY, USA, 1988.

18. Hopkins, W.G. Measures of Reliability in Sports Medicine and Science. Sport. Med. 2000, 30, 1-15. [CrossRef]

19. Malina, R.; Bouchard, C.; Bar-Or, O. Growth, Maturation, and Physical Activity, 2nd ed.; Human Kinetics: Champaign, IL, USA, 2004.

20. Kavvoura, A.; Zaras, N.; Stasinaki, A.N.; Arnaoutis, G.; Methenitis, S.; Terzis, G. The importance of lean body mass for the rate of force development in taekwondo athletes and track and field throwers. J. Funct. Morphol. Kinesiol. 2018, 3, 1-20. [CrossRef] 
21. Balsalobre-Fernández, C.; Tejero-González, C.M.; Del Campo-Vecino, J.; Bachero-Mena, B.; Sánchez-Martínez, J. Differences of muscular performance between professional and young basketball players. Cult. Cienc. y Deport. 2016, 11, 61-65. [CrossRef]

22. Wissel, H. Basketball: Steps to Success; Human Kinetics: Champaign, IL, USA, 1994.

23. Liu, S.; Burton, A.W. Changes in basketball shooting patterns as a function of distance. Percept. Mot. Skills 1999, 89, 831-845. [CrossRef]

24. Etnyre, B.R. Accuracy characteristics of throwing as a result of maximum force effort. Percept. Mot. Skills 1998, 86, 1211-1217. [CrossRef] [PubMed]

25. Knudson, D. Biomechanics of the Basketball Jump Shot-Six Key Teaching Points. J. Phys. Educ. Recreat. Dance 1993, 64, 67-73. [CrossRef]

26. Hudson, J. Shooting techniques for small players. Athl. J. 1985, 11, 22-24.

27. Darling, W.; Cooke, J. Changes in the variability of movement trajectories with practice. J. Mot. Behav. 1987, 19, 291-309. [CrossRef] [PubMed]

28. Schmidt, R.; Zelaznik, H.; Hawkings, B.; Frank, J.; Quinn, J., Jr. Motor-output variability: A theory for the accuracy of rapid motor acts. Psychol. Rev. 1979, 47, 415-451. [CrossRef]

29. García, J.A.; Sabido, R.; Barbado, D.; Moreno, F.J. Analysis of the relation between throwing speed and throwing accuracy in team-handball according to instruction. Eur. J. Sport Sci. 2013, 13, 149-154. [CrossRef]

Publisher's Note: MDPI stays neutral with regard to jurisdictional claims in published maps and institutional affiliations. 